\title{
Mechanical and Tribological Properties of Nitrile Rubber Reinforced by SiO2: Molecular Dynamics Simulation Mechanical and Tribological Properties of Nitrile Rubber Reinforced by SiO2: Molecular Dynamics Simulation
}

Xueshen Liu ( $\square$ liuxueshen224@126.com )

Wuhan University of Technology School of Energy and Power Engineering

Xincong Zhou

Wuhan University of Technology

Fuming Kuang

Wuhan University of Technology

Houxiu Zuo

Wuhan University of Technology

Jian Huang

Wuhan University of Technology

\section{Research Article}

Keywords: mechanical and tribological properties, nitrile rubber, molecular dynamics simulation, nano$\mathrm{SiO} 2$

Posted Date: March 11th, 2021

DOl: https://doi.org/10.21203/rs.3.rs-194024/v1

License: (9) This work is licensed under a Creative Commons Attribution 4.0 International License. Read Full License

Version of Record: A version of this preprint was published at Tribology Letters on April 9th, 2021. See the published version at https://doi.org/10.1007/s11249-021-01427-9. 


\section{Abstract}

This paper investigated the mechanism of enhancing the mechanical and tribological properties of nitrile rubber (NBR) with SiO 2 on the molecular scale. Molecular dynamics (MD) simulations were performed on molecular structure models of pure NBR, NBR/SiO 2 and three-layer friction pairs. The results showed that the hydrogen bonds and interfacial interaction between SiO 2 and NBR molecular chains decreased the fractional free volume of NBR nanocomposites, and increased the shear modulus of NBR by $25 \%$ compared with that of pure NBR. During the friction process, SiO 2 decreased the radius of gyration of NBR molecular chains and effectively lowered the peak atomic velocity, the peak temperature and the peak friction stress at the interface between NBR and copper atoms. The average friction stress on NBR/SiO 2 was $34 \%$ lower than that on NBR, which meant the tribological properties of NBR were significantly improved by SiO 2 . The mechanism of SiO 2 reinforcing NBR on a molecular scale can lay a theoretical foundation for the design of water-lubricated rubber bearings.

\section{Full Text}

Due to technical limitations, full-text HTML conversion of this manuscript could not be completed. However, the latest manuscript can be downloaded and accessed as a PDF.

\section{Figures}

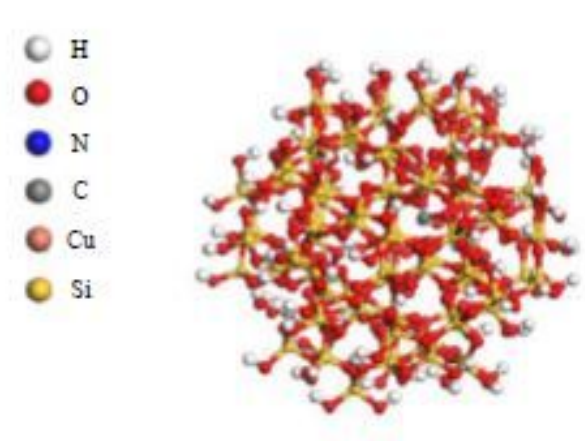

(a) The spherical model of Nano$\mathrm{SiO}_{2}$ with diameter of $1 \mathrm{~nm}$

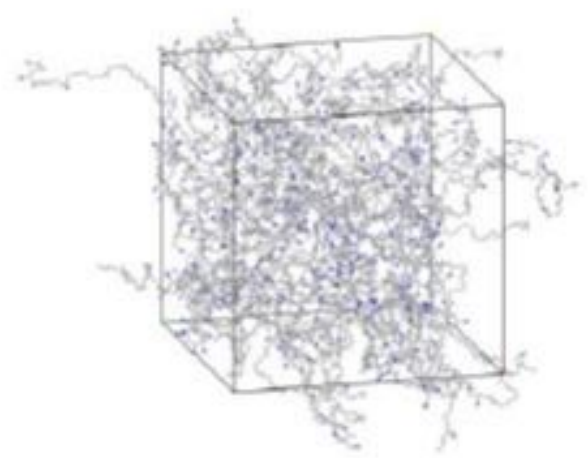

(e) Pure NBR periodic cell model

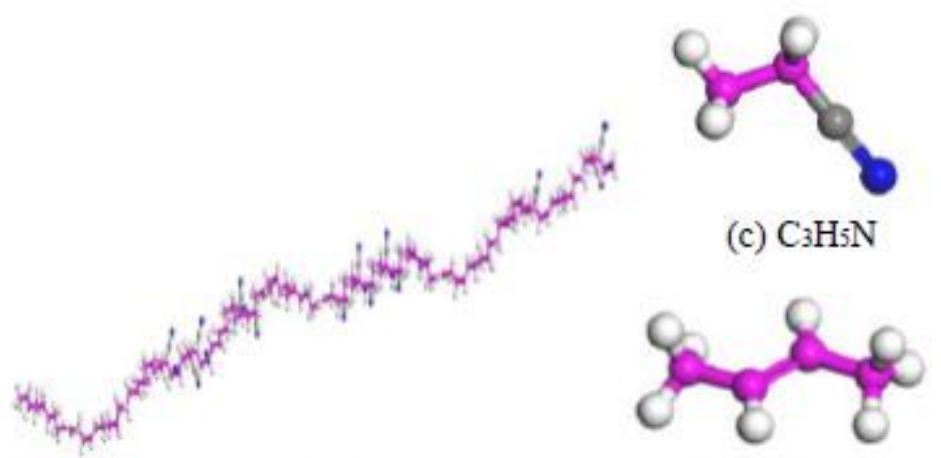

(b) NBR Chain

(d) $\mathrm{C}_{4} \mathrm{H}_{8}$

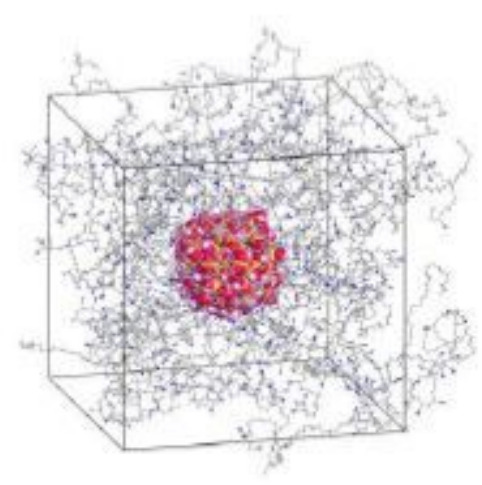

(f) $\mathrm{NBR} / \mathrm{SiO}_{2}$ periodic cell model 
Figure 1

The structural model of NBR filled with nano-SiO2 (SiO2 (TESPT))

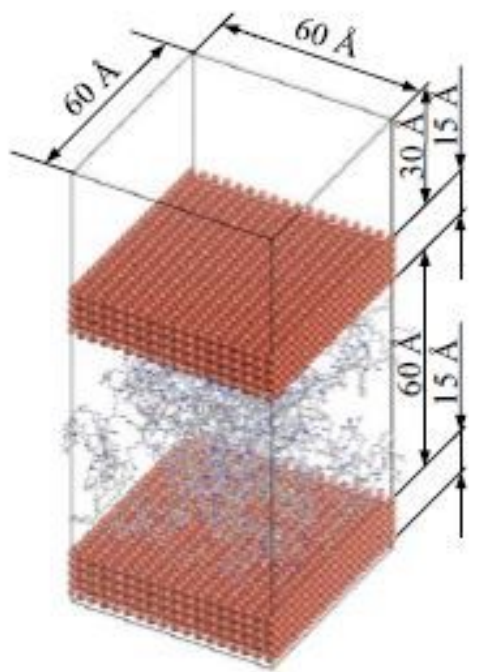

(a)

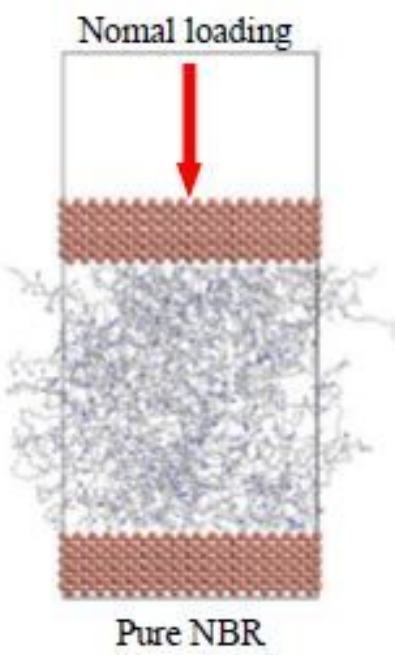

(b)

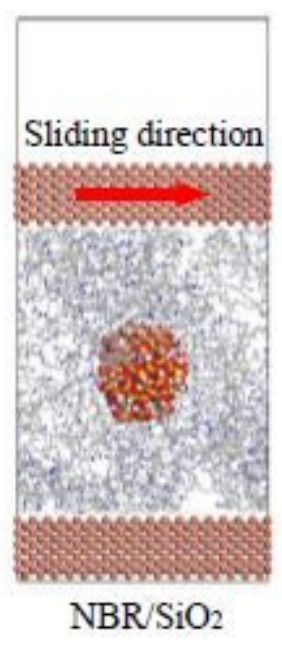

(c)

\section{Figure 2}

Three-layer molecular models for shear friction pairs
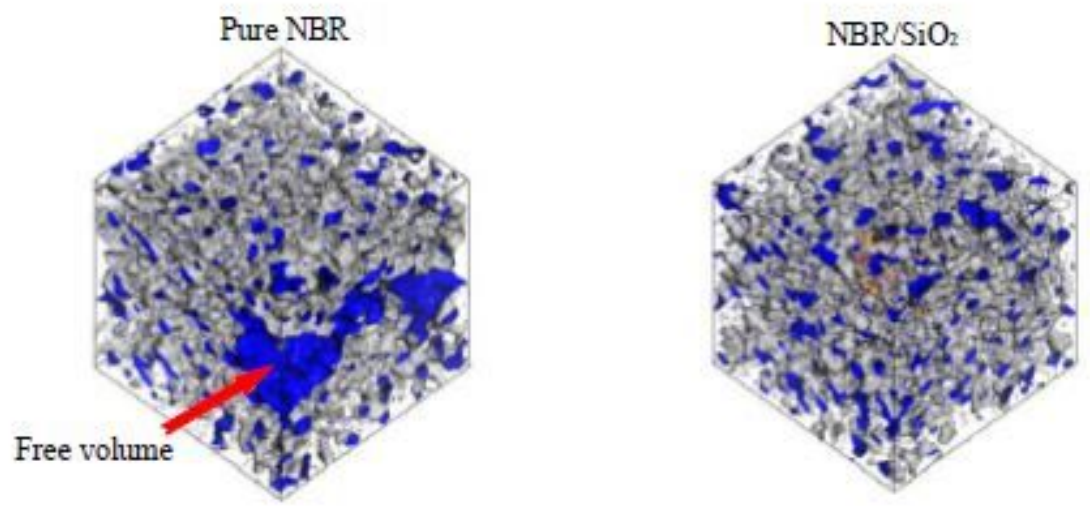

The free volume fraction goes down

\section{Figure 3}

Free volume of pure NBR and NBR/SiO2 

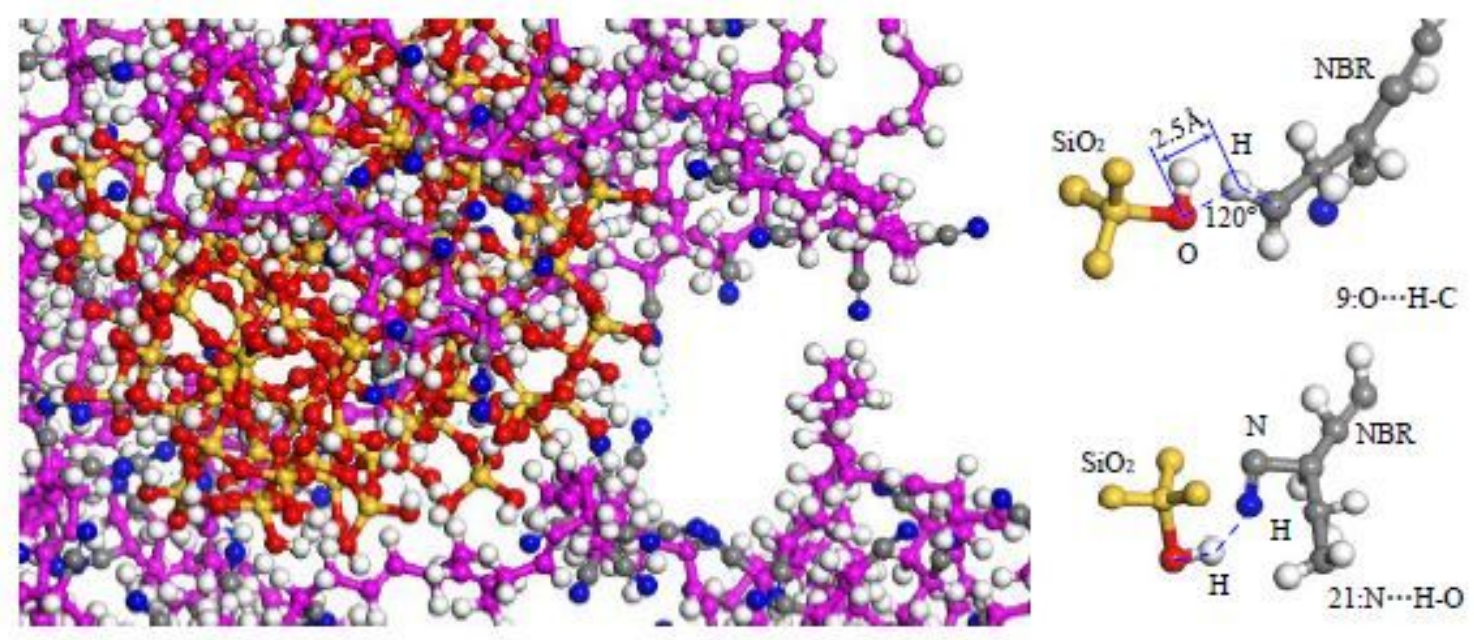

Figure 4

The hydrogen bonds formed between nano-SiO2 and NBR
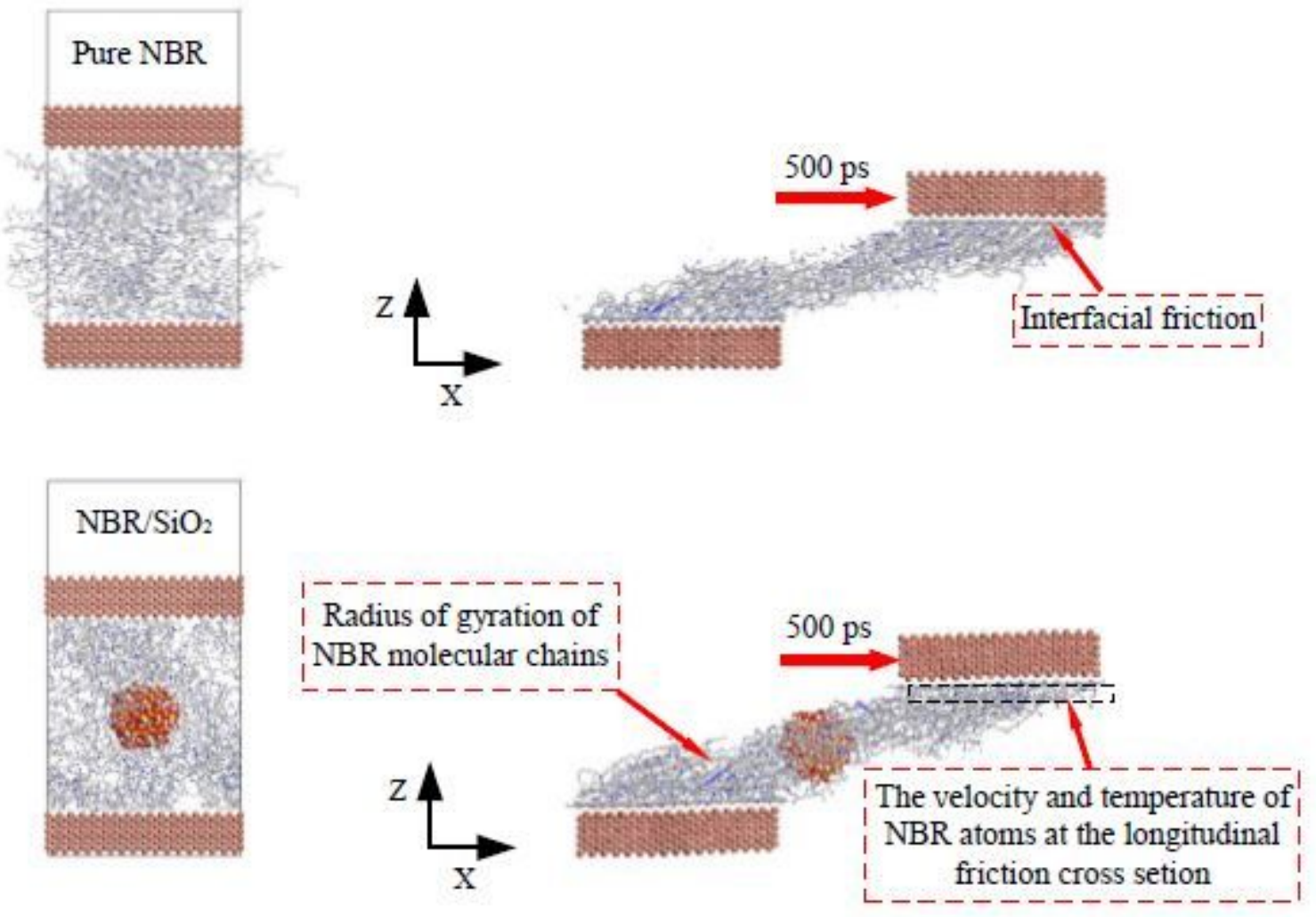

Figure 5

Pictures of shear friction simulation for pure NBR and NBR/SiO2 


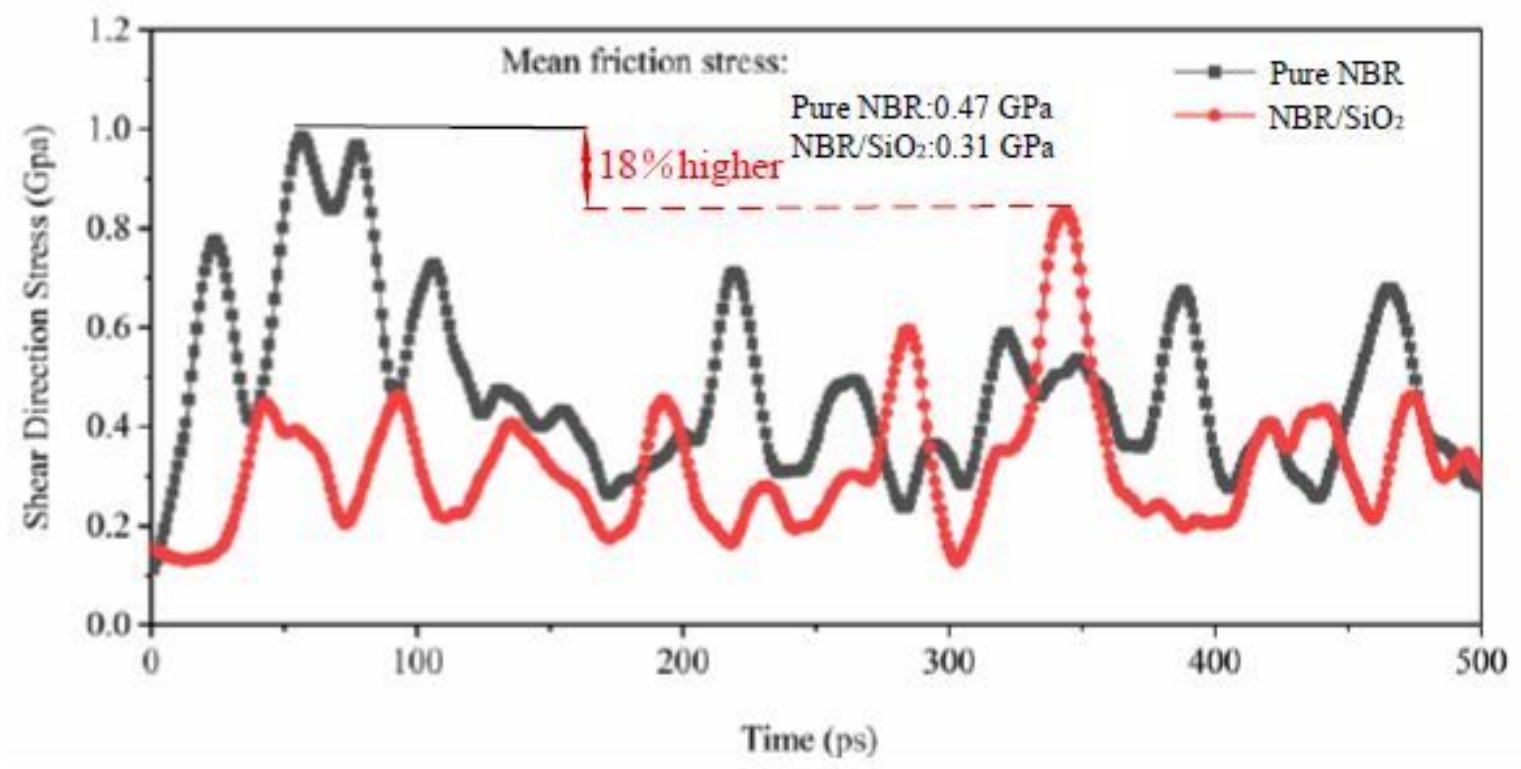

Figure 6

The friction stress between copper atoms and pure NBR (NBR/SiO2) during the friction process

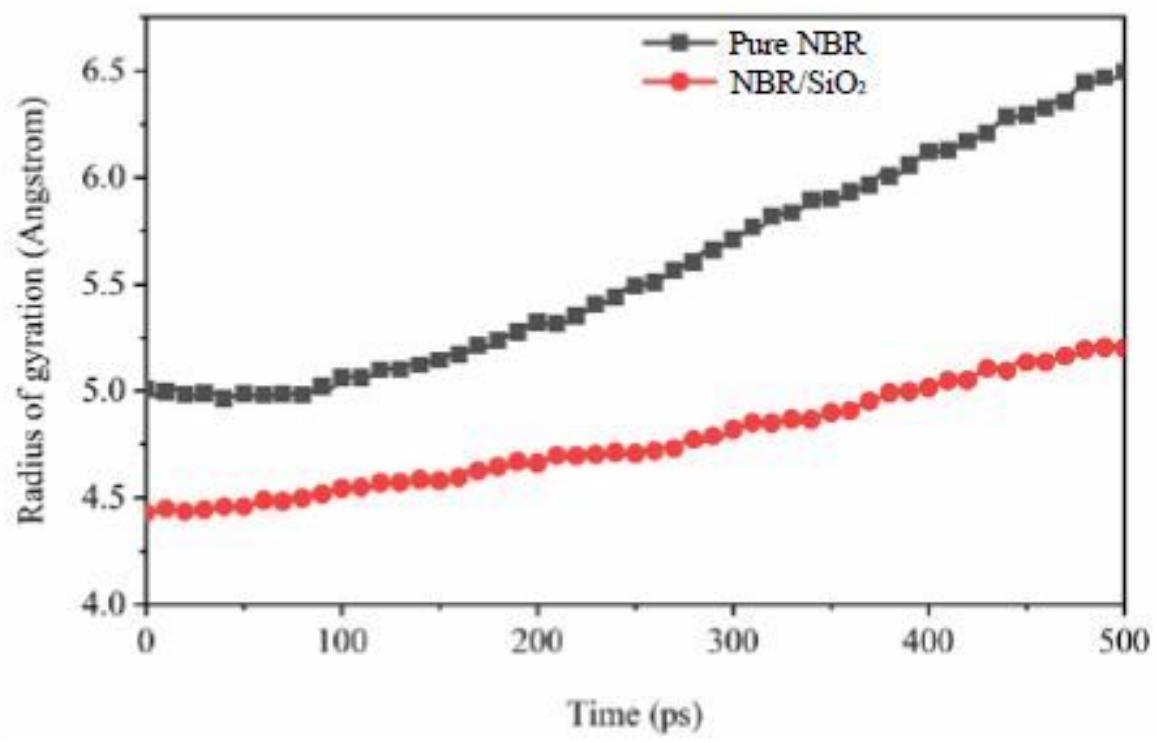

Figure 7

The radius of gyration of NBR molecular chains in pure NBR and NBR/SiO2 during friction process 


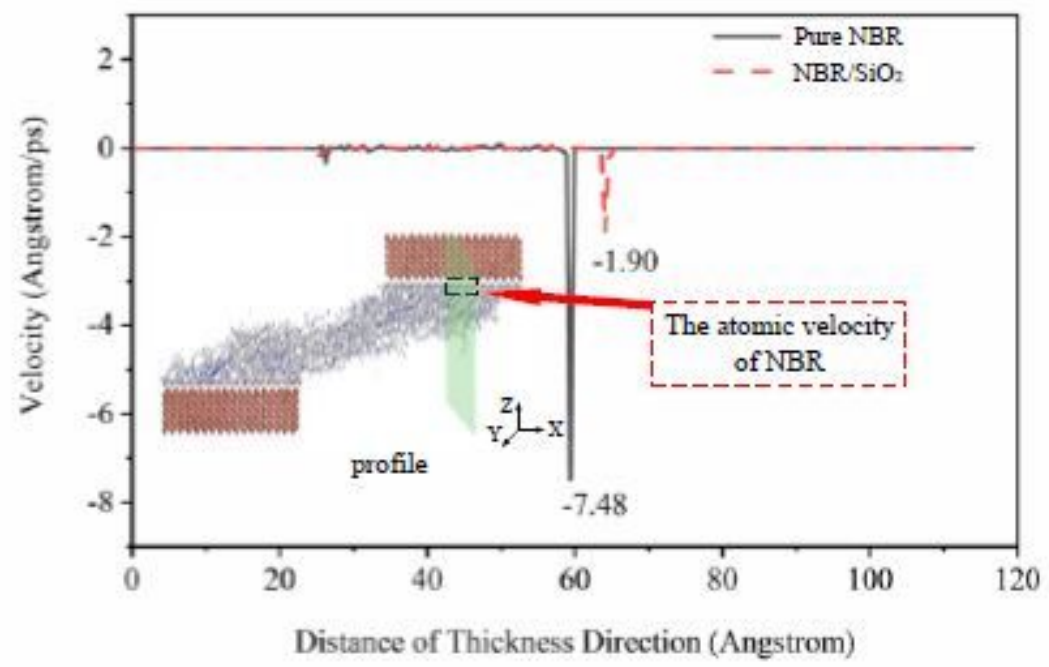

Figure 8

Atomic velocity in the longitudinal profile of pure NBR and NBR/SiO2

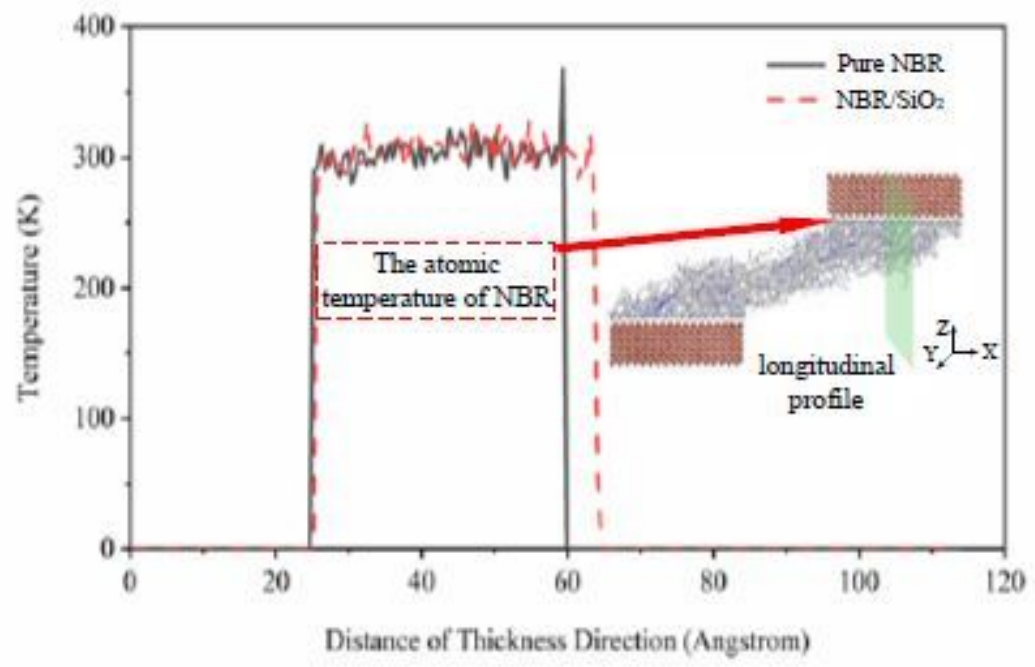

Figure 9

Temperature in the longitudinal profile of pure NBR and NBR/SiO2 


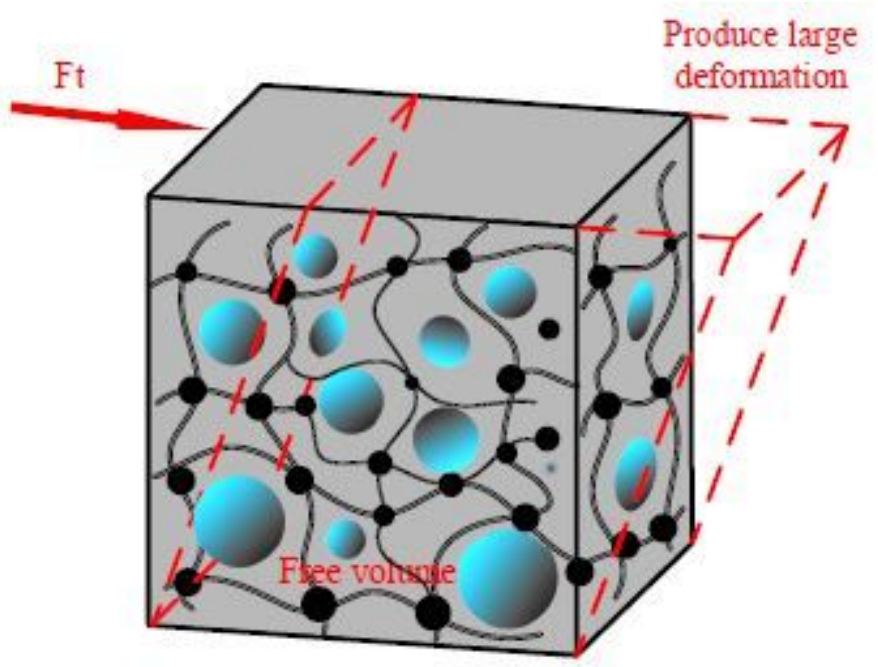

(a)

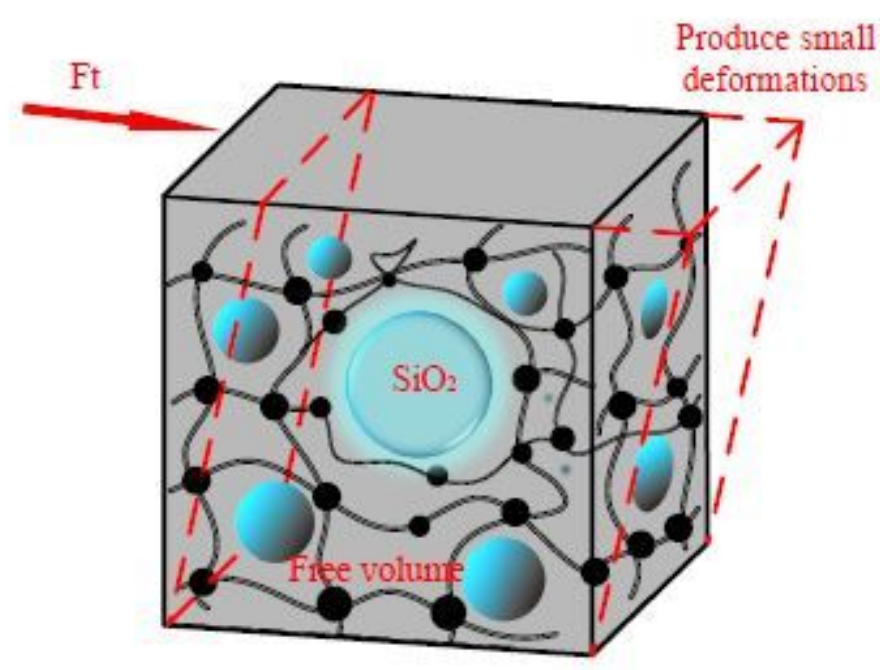

(b)

Figure 10

Schematic of mechanical properties of SiO2-reinforced NBR 


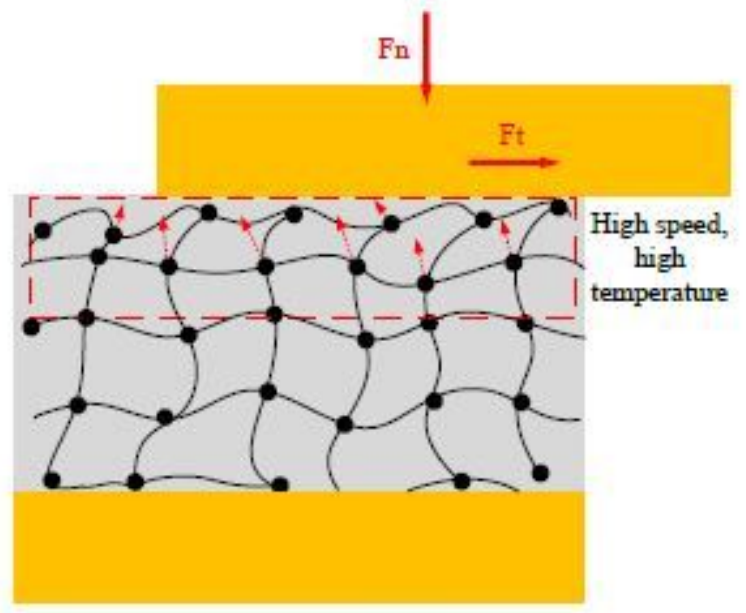

(a)

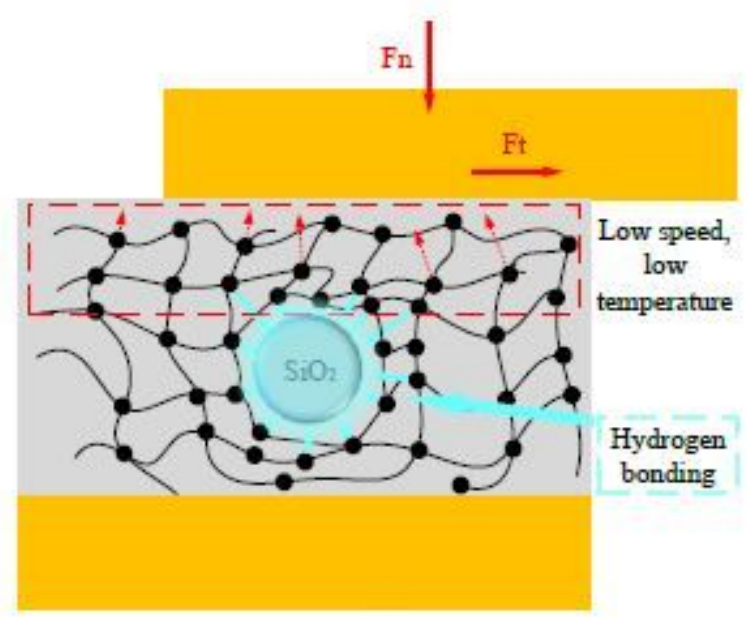

(b)

\section{Figure 11}

Schematic diagram of tribological properties of SiO2-reinforced NBR 